\title{
proximaçōes das funções de Vladimir Propp ao enredo de Grande sertão: veredas, de João Guimarães Rosa
}

Wagner Dias dos Santos 1

Resumo: O presente artigo pretende pontuar aproximações de algumas funções de Vladimir Propp, presentes na Morfologia do Conto Maravilhoso, ao enredo de Grande sertão: veredas de João Guimarães Rosa. Na análise do fragmento, comumente chamado de "Primeiro encontro", foi possível observar o deslize constante dos personagens Riobaldo e Diadorim, como se não pudessem ser apreendidos facilmente em algumas categorizações. Nesse sentido, a metáfora proposta por Rosa, sugerida pela palavra travessia, evidencia sempre novas dimensões nas tentativas de mergulho nesse grande texto.

\section{Palavras-chave: narrativa, discurso, literatura}

\begin{abstract}
The present article intends to ponctuate approaches of some functions of Vladimir Propp, present in the Morfologia do Conto Maravilhoso, to the plot of Grande sertão: veredas from João Guimarães Rosa. In the analysis of the fragment, usually called "Primeiro encontro", was possible to observe the constant slip of the characters Riobaldo and Diadorim, as if they could not easily be apprehended in some categorizations. In this direction, the metaphor proposal for Rose, suggested for the word crossing, always evidences new dimensions in the attempts of diving in this great text.
\end{abstract} Linguagem pela Faculdade de Educação da Universidade de São Paulo. Membro do GEPPEP Grupo de Estudos e Pesquisa Produção Escrita e Psicanálise. 
O livro Grande sertão: veredas, do escritor João Guimarães Rosa, já foi e tem sido objeto de inúmeros estudos desde a sua publicação em 1956. Recuperando aqui, em parte, as palavras enunciadas pelo professor Antonio Candido, em maio de 2006, no Instituto de Estudos Brasileiros - IEB-USP, conferência realizada por ocasião das comemorações do cinqüentenário dessa obra, o crítico literário referia-se ao livro dizendo tratar-se de "um trabalho monumental que ultrapassava, em boa medida, outras criações do próprio João Rosa, como Campo Geral ou Sagarana”. Continuando suas considerações, Antonio Candido disse ter tido, naqueles idos 1956, uma experiência "física" com aquela leitura, ficando perturbado por alguns dias, pela tamanha novidade com a qual se deparava. Assim, enquanto alguns condenavam os "abusos" de linguagem do autor em Grande sertão: veredas, o professor Candido tomou para si a saga do jagunço Riobaldo como uma das mais instigantes invenções na literatura universal.

Em que se pese este parágrafo inicial, após cinqüenta e dois anos passados da primeira edição deste romance, hoje, não resta muita dúvida sobre a grandeza dos traços deixados ali por Rosa. Por outro lado, a bibliografia ligada à pesquisa dos textos rosianos, incluindo textos anteriores e posteriores ao Grande sertão: veredas, cresce a cada dia. Novas leituras são feitas, sejam no terreno da teoria literária, no das artes, da psicanálise, da geografia e, até mesmo, em áreas como botânica e zoologia. É possível ouvir de Dieter Heidemman, professor titular do Departamento de Geografia da Universidade de São Paulo, que em suas aulas sobre o cerrado ou específicas formações das regiões do norte e do oeste de Minas Gerais, áreas-fronteiras com a Bahia e com o Centro-oeste brasileiro, não há referências tão peculiares quanto aquelas deixadas por João Guimarães Rosa.

Nesse sentido, situa-se o roteiro deste artigo, que tentará abraçar algumas noções extraídas da Morfologia do conto maravilhoso, de Vladimir I. Propp, na convergência desses estudos e dessas leituras, na trajetória/travessia do "herói" Riobaldo, do Grande sertão: veredas. Evidentemente, reconhece-se de imediato que em qualquer obra com características similares as desse livro, isto é, construído e requisitado historicamente como um clássico e, às vezes, descrito como epopéia, há relativa facilidade de diálogo com algumas das chamadas "funções" de Vladimir Propp, que serão tratadas mais adiante. Assim, para propósito dessas linhas, está instaurada a crença que nessa formulação pretendida seja provocado, minimamente, um modo de dizer que traga possibilidades de se pensar, por um lado, aspectos ligados à apreensão dessa grande obra na cultura chamada popular e, por outro, aponte para algumas possibilidades metodológicas vinculadas às funções de Vladimir Propp.

Antes que sejam trazidas as noções de Propp, com aproximações possíveis feitas ao texto rosiano, o dizer do parágrafo anterior: "a apreensão de Grande sertão na cultura popular", talvez, mereça ilustrações ou uma melhor apreciação. Atualmente, é bem conhecido o Parque Grande sertão: veredas, que se situa na Serra das Araras - no norte de Minas Gerais. Do mesmo modo, desde 2004, funciona na região o Circuito Turístico João Guimarães Rosa, que hoje envolve aproximadamente vinte municípios; entre eles: Cordisburgo, cidade natal de João Rosa; Andrequicé, cidade do famigerado vaqueiro Manuelzão; Morro da Garça, também cenário de o Recado do Morro.

Cabe aqui dizer que tal Circuito começou com treze cidades e que, muito rapidamente, estimulou a corrida de vários municípios a reivindicarem sua participação no "bolo", por serem citados de maneira direta ou indireta no romance Grande sertão. Com esse exemplo, pode-se arriscar dizer que essa saga sertaneja, vivida por Riobaldo e Diadorim, é uma história que não pôde mesmo se esgotar em pesquisas ou textos acadêmicos. Ela foi derivando variações bem inusitadas, com diversas manifestações populares. Pode-se dizer, brincando com os paradoxos, que o Grande sertão: veredas prossegue e permanece fixado em sua travessia. 
Dirigindo agora o olhar para o trabalho de Vladimir Propp, Morfologia do conto maravilhoso, também tratado pelo autor como um estudo sobre "os contos de magia”, é possível configurar um método de análise textual estruturado sob funções "reconhecíveis", isto é, passíveis de classificação, ligadas a personagens de contos ou de enredos romanceados. Propp parte de um estudo específico e, em suas palavras, "por conto de magia entenderemos, por enquanto, os que estão classificados no índice de Aarne e Thompson entre os números 300 e 749". (PROPP, 1984: 25)

Se a amostragem apontada inicialmente por Propp é bem pontual, localizada num gênero, o resultado extraído do seu estudo pôde abrir caminho para a aplicação das chamadas funções em outras narrativas. Nesse sentido, o romance Grande sertão: veredas assumirá aqui o papel de conto de magia, todavia, não como representante direto desse gênero, mas, de outra maneira, como abrigado na literalidade da frase: é um "conto maravilhoso".

Tal como a história contada pelo personagem Riobaldo, em forma de reminiscências, as linhas deste artigo não obedecerão a uma linearidade possível, isto é, a identificação ou a seqüência das funções de Propp será apresentada de forma irregular ou alternada e, por vezes, utilizada reincidentemente. Por outro lado, pode-se dizer que a pretensão de se fazer aproximação das funções de Propp a essa obra de João Guimarães Rosa, muitas vezes, esbarra na dificuldade de classificação de cenas e de personagens - dado o caráter ambíguo de algumas aparições.

Se Riobaldo, de antemão, como enunciador da saga e personagem central dos eventos, apresenta-se com as características do "herói", mais na frente, com o desenrolar da história, outros personagens vão ocupando e desocupando este lugar, deslocando o leitor para a composição de micronarrativas dentro dessa grande narrativa. É assim, voltando à tópica da apreensão do livro na cultura popular, que contadores de estórias nas cidades de Cordisburgo e AndrequicéMG apresentam o Grande sertão: veredas em fragmentos como: "O primeiro encontro", "O julgamento de Zé Bebelo", "O liso do Suçuarão", "O pacto", "Maria Mutema”, "A matança dos cavalos", "Nhorinhá" ou "A batalha final”.

Nesses recortes, os papéis vão se alternando e fica bastante difícil classificar os personagens univocamente. É possível dizer que, ao final da história, ficam múltiplas possibilidades de leitura, que podem mesmo levar o leitor a tal experiência física, mencionada pelo professor Antonio Candido em sua conferência de 2006. Fica em ziguezague a desconfiança que o Diabo se manifesta no próprio narrador ou ainda no Senhor a quem ele se dirige - vivendo em lembrança os momentos de luz e de treva na travessia que é o sertão.

Feita a eleição de um trecho do livro Grande sertão veredas, o chamado "Primeiro encontro" de Riobaldo e Diadorim, quando ainda adolescentes, será naturalmente possível sugerir marcas propostas pelo Propp da Morfologia: "a saída de um dos membros de casa”; "a proibição ou a ordenação imposta ao herói”; "a transgressão a uma designação"; "a aproximação de um antagonista - que procura uma informação"; "o prejuízo feito pelo antagonista”; e muitas outras funções. No entanto, é importante admitir que a ferramenta extraída da elaboração proppiana, aqui terceirizada, deve legitimamente carregar os seus limites. Por isso, essa pequena elaboração pretende dar conta, porém, de um modo bastante superficial, da "nomeação" de alguns personagens, na cena supracitada.

O chamado "Primeiro encontro" vem antecedido dos motivos que levaram Riobaldo a encontrar aquele menino - o Reinaldo. É bom mencionar que nesse primeiro contato os dois personagens não trocaram nomes; e foram se entrelaçando pela simpatia mútua. Riobaldo estava em doença quando sua mãe fez promessa pra Santo - que livrasse o menino do mal. Ela prometeu que 
quando o filho se curasse designaria a ele que fosse ao Porto do de-Janeiro, local de comércio, em busca de esmolas - que serviriam como pagamento pela graça recebida. Na narração de Riobaldo, eis as palavras:

Pois tinha sido que eu acabava de sarar de uma doença, e minha mãe feito promessa para eu ir cumprir quando ficasse bom: eu carecia de tirar esmola, até perfazer um tanto - metade para se pagar uma missa, em alguma igreja, metade para se pôr dentro duma cabaça bem tapada e breada, que se jogava no São Francisco, a fim de ir, Bahia abaixo, até esbarrar no Santuário do Santo Senhor Bom-Jesus da Lapa, que na beira do rio tudo pode. (ROSA, 1986: 85)

A ida do menino Riobaldo ao Porto do de-Janeiro não foi uma saída corriqueira. Afinal, o seu afastamento de casa, a sua missão, tinha uma finalidade incisiva: o pagamento da promessa que a mãe tinha feito. Entre o Porto e o corpo do menino, a distância medida em passos; pés que o guiavam movidos pela dívida da mãe, pela ordem santa. O esmolar era uma novidade para ele. Ao mesmo tempo, o lugar Porto abria as perspectivas para um mundo desconhecido: de negócios, de paisagens diversas. Na opção por essa cena, isto é, do andar do menino Riobaldo na trilha que o levará a conhecer Reinaldo-Diadorim, desenhase também a escolha da primeira função proppiana; a saber: "a saída de casa", mais especificamente, "o afastamento".

Esse afastamento, quando relacionado a essa cena do Grande sertão, ganha uma dimensão interessante, pois Riobaldo, antes de assumir pra si a promessa da mãe, põe seu olhar no mundo que o rodeia. Deste modo, o afastamento do menino é em relação, por um lado, aos hábitos de casa, por outro, um distanciamento dele nele mesmo. Para Propp, a simples ida do menino ao Porto caracterizaria a função I da Morfologia, pelo seguinte enunciado: "às vezes, são os membros da geração mais nova que se afastam. Vão fazer uma visita, pescar, passear, apanhar frutas". (PROPP, 1984: 32)

A história continua e Riobaldo vai ao Porto dia após dia. Na promessa, a mãe havia estimado um valor que pudesse pagar a missa e justificar a "viagem" da cabaça, enviada rio abaixo, para o Santuário do Santo Senhor Bom-Jesus da Lapa. O menino Riobaldo esperava por lá, com a sacola da mãe, "naquele parado, raro que alguém vinha". No entanto, ele gostando, apreciava os barrancos - a novidade quieta pros seus olhos. Três ou quatro dias de idas ao Porto, o encontro com um menino.

\footnotetext{
Aí pois, de repente, vi um menino, encostado numa árvore, pitando cigarro. Menino mocinho, pouco menos do que eu, ou devia regular minha idade. Ali estava, com um chapéu-de-couro, de sujigola baixada, e se ria pra mim. Não se mexeu. Antes fui eu que vim pra perto dele. Então ele foi me dizendo, com voz muito natural, que aquele comprador era o tio dele, e que moravam num lugar chamado Os-Porcos, meio mundo diverso, onde não tinha nascido. Aquilo ia dizendo, e era um menino bonito, claro, com a testa alta e olhos aos-grandes, verdes. Muito tempo mais tarde foi que eu soube que esse lugarim OsPorcos existe de se ver, menos longe daqui, nos gerais de Lassance. (ROSA, 1986: 85- 86)
}

O primeiro encontro de Riobaldo com o menino foi também de um olhar com um sorriso. Atraído pela expressão da face e pelos contornos do menino pitando um cigarro, Riobaldo se aproxima com curiosidade de descoberta, possivelmente, de algo que o ultrapassava - no gesto, na pose, na apresentação daquele outro. Na narração, o fascínio que a imagem daquele menino, que tempos depois, na trama do Grande sertão, será identificado como Reinaldo ou Diadorim, causou em Riobaldo é uma espécie de síntese do que pode ser chamado de transformação, metaforicamente indicado por Guimarães Rosa, em vários momentos do livro, como travessia. 
Assim, a recuperação dessa e de tantas outras cenas, na narrativa desse homem do sertão, indica um percurso, um atravessamento, que o leva a agir de um modo ou de outro - conforme as circunstâncias. Pode-se pensar que, nesse primeiro encontro, Riobaldo foi imantado pelo sorriso do menino e sua ação é decorrente de uma espécie de feitiço momentâneo. Contudo, a marca dessa primeira troca será tão profunda que, no enredo, pode ser entendida como um rito de passagem. Para tanto, é necessário que se avance um pouco mais na história.

Foi Reinaldo quem dirigiu primeiramente a palavra a Riobaldo, dizendo de sua morada e do tio que estava ali a negócios. O diálogo se inicia e Riobaldo se sente tocado, quase hipnotizado, por essa conversa. Assim Riobaldo diz do menino Reinaldo:

Ele falava sem mudança, nem intenção, sem sobejo de esforço, fazia de conversar uma conversinha adulta e antiga. Fui recebendo em mim um desejo que ele não fosse mais embora, mas ficasse, sobre as horas, e assim como estava, sem parolagem miúda, sem brincadeira - só meu companheiro amigo desconhecido". (Idem, ibidem: 86)

Esse momento é importante para o propósito da aproximação de Grande sertão a algumas funções presentes na Morfologia de Propp. Como se indicou anteriormente, o afastamento de Riobaldo corresponde à primeira função proppiana, contudo, é bom salientar que, ao sair de casa para cumprir uma promessa, sob orientação ou ordem da mãe, Riobaldo está diante também de um interdito uma proibição. Essa proibição está diretamente ligada à idéia de que ele deverá, necessariamente, recolher e "perfazer" o valor, em esmolas, previsto para que o contrato com a mãe se cumpra. No entanto, um terceiro pode ameaçar essa ordem e, num certo sentido, pode ser chamado de antagonista.

A terceira função de Propp diz respeito à proibição transgredida e a quarta ao antagonista que procura uma informação. Se em Grande sertão, a partir das funções de Propp, por um lado é possível caracterizar os papéis de alguns personagens, por outro, esses mesmos papéis podem ser trocados, em variadas circunstâncias. Reinaldo Diadorim poderá ser tratado como antagonista aqui nesse "primeiro encontro", mas, num sentido muito restrito. Ele, propriamente, não causará dano ao "herói" aqui eleito, talvez precipitadamente. Diferentemente, ele vai inocular algo que determinará a vida desse herói - em termos de criação e de destruição, misturadamente. Diadorim não interroga Riobaldo; mas, ele causa a interrogação. Abre o caminho para o desconhecido.

$\mathrm{Na}$ terminologia de Propp, que papel seria mais adequado a Diadorim? Certamente não se pode caracterizá-lo como antagonista, senão de forma difusa, então, pode-se revesti-lo no papel de um segundo herói? Sem dúvida, no Grande sertão: veredas há muitos heróis, considerando as inúmeras narrativas que foram sugeridas anteriormente: Joca Ramiro, Zé Bebelo, Marcelino Pampa, entre outros. No entanto, no episódio escolhido aqui, "O primeiro encontro" de Riobaldo e Diadorim, parece que a cena é do menino Diadorim. No entanto, ainda assim fica difícil qualificá-lo como herói. Então, como devemos ler essa passagem?

$\mathrm{O}$ que se pode pontuar aqui é um tipo de deslize desse personagem diante das funções sugeridas por Propp. Diadorim não se apreende facilmente, pois, de um certo modo, possui características divinas ou misteriosas. Talvez, numa perspectiva reduzida, atualizá-lo seria compor a sua presença, nesse primeiro encontro, como o meio mágico para a travessia do, agora sim, herói Riobaldo.

Essa interpretação pode ser arriscada, contudo, alguns indícios podem levar a ela. Diadorim se apresenta pela primeira vez em sorriso, fascinante, e, se possível dizer, imóvel, como o primeiro motor aristotélico - o próprio Deus. Por atração chama Riobaldo que, se aproximando, confirma a luz irradiante. A voz de Diadorim leva tranqüilidade e paz a Riobaldo, que se esquece no estar ali no 
Porto do de-Janeiro, por ordenança da mãe, no cálculo de esmolas. Contudo, essa figura nova, em forma do menino Reinaldo Diadorim, carrega consigo mais mistério do que essa primeira abordagem pode revelar.

Pouco depois, os dois meninos estavam unidos em canoa, navegando o de-Janeiro, "agora num fora do tempo", juntamente com um canoeiro. À entrada na canoa, valem aqui as palavras de Riobaldo:

\footnotetext{
O menino tinha me dado a mão para descer o barranco. Era uma mão bonita, macia e quente, agora eu estava vergonhoso, perturbado. $O$ vacilo da canoa me dava um aumentante receio. Olhei: aqueles esmerados esmartes olhos, botados verdes, de folhudas pestanas, luziam um efeito de calma, que até me repassasse. Eu não sabia nadar. $\bigcirc$ remador, um menino também, da laia da gente, foi remando. Bom aquilo não era, tão pouca firmeza. Resolvi ter brio. Só era bom por estar perto do menino. Nem em minha mãe eu não pensava. Eu estava indo ao meu esmo. (Idem, ibidem: 87)
}

Ir a seu esmo, obter novidade quieta para os olhos era sinônimo de liberdade para Riobaldo. No entanto, essa liberdade vinha carregada também de insegurança, trazida pelo mistério daquele "canoar" inusitado. As sensações se misturavam naquela descoberta e a paisagem crescia diante dos olhos de Riobaldo: a fauna e a flora deslumbrantes, vivas, em sons e movimentos no "vacilo" daquela canoa. Tudo isso e a mais estranha/fascinante figura do menino Diadorim - que "era dessemelhante", não dando "minúcia de pessoa outra nenhuma”. E chegaram mesmo na confluência do de-Janeiro com o Rio São Francisco. O pavor de Riobaldo, naquela experiência, é nítido. Foi "de repentemente, aquela terrível água de largura: imensidade".

Medo maior que se tem, é de vir canoando num ribeirãozinho, e dar, sem espera, no corpo dum rio grande. Até pelo mudar. A feiúra com que o São Francisco puxa, se moendo todo barrento vermelho, recebe para si o de-Janeiro, quase só um rego verde só. (Idem, ibidem: 88)

Deparar-se com o grande Chico naquelas condições, isto é, com uma canoinha de pau "burro", que naufraga facilmente, com a inaptidão para o nado, com um menino misterioso e um outro desconhecido, foi sentimento ímpar para Riobaldo. $O$ medo e a vontade de voltar ao ponto de partida convergiram numa mesma frase-pedido: "daqui vamos voltar?" Para tal pergunta, Diadorim manifesta a única resposta possível para o funcionamento do enredo, dirigida em forma de exclamação, não a Riobaldo, mas, ao canoeiro: “atravessa!". E a travessia é impulsionada. Riobaldo se agarra no pau da canoa e transparece todo em seu medo de "não sei nadar". Diadorim anuncia também não saber da ciência do nado e que ali só "carecia de ter coragem". Mais explicitamente, o menino de "folhudas pestanas" disse ser filho do homem mais valente do mundo.

Pedindo ao remador que encostasse a canoa e que esperasse por eles, Diadorim desceu com Riobaldo mata adentro. Foram caminhando e, por fim, sentaram-se em lugar fresco de clareira para descanso e papéis de comensais rapadura e queijo comprados no Porto do de-Janeiro. Na cena que se segue é possível sublinhar a aparição ameaçadora de um característico antagonista, como proposto na quarta função de Vladimir Propp. No dizer de Riobaldo:

Antojo, então, por detrás de nós, sem avisos, apareceu a cara de um homem! As duas mãos deles afastavam os ramos do mato, me deu um susto somente. Por certo algum trilho passava por perto ali, o homem escutara nossa conversa. À fé, era um rapaz, mulato, regular uns dezoito ou vinte anos; mas altado, forte, com as feições muito brutas. Debochado, ele disse isto: - "Vocês dois, uê, hem?! Que é que estão fazendo?..." Aduzido fungou, e, mão no fechado da outra, bateu um figurado indecente. (idem, ibidem: 90) 
É possível que o mulato tenha percebido a chegada da canoa e investigado o caminhar dos meninos na mata. A informação é clara: dois moleques, fracos, facilmente domináveis. Essa conclusão pode ser extraída da própria ação do mulato. No momento em que ele pergunta: "que é que estão fazendo?" há quase que simultaneamente a investida sobre os dois. Como coação, o mulato se vale de seu porte físico e de uma aparente visão privilegiada da condição de suas vítimas. Aqui outras funções de Propp podem ser associadas ao texto: a tentativa do antagonista de ludibriar a vítima; a dissimulação do herói - mantendo-se numa posição de fraqueza, o combate efetivo entre herói e antagonista, o castigo ao inimigo etc. É bom enfatizar que, nesse momento, o menino Diadorim é a própria manifestação do herói. Riobaldo revela-se em sua fraqueza, sendo guiado pelos passos de seu amigo desconhecido.

Vendo o mulato, Diadorim permanece deitado, em posição de descanso, diante da aparição e do versejar do antagonista. Após isso, dissimula, insinuando a possibilidade de um enlaçamento em "sujices" com o ameaçador: "você, meu nego? Está certo, chega aqui..." Lado a lado com o mulato, crava-lhe a faca e extrai o sangue legítimo da ameaça. Afugenta-o - com resposta de lâmina brilhante. Riobaldo se impressiona demais com a coragem de Reinaldo. Dirigise a ele com a veia do aprendizado:

Você é valente sempre? - em hora perguntei. $\bigcirc$ menino estava molhando as mãos na água vermelha, esteve tempo pensando. Dando fim, sem me encarar, declarou assim: "Sou diferente de todo mundo. Meu pai disse que eu careço de ser diferente, muito diferente ..." (idem, ibidem:92)

E daí o sentimento de transformação em Riobaldo:

E eu não tinha medo mais. Eu? O sério pontual é isto, o senhor escute, me escute mais do que eu estou dizendo; e escute desarmado. O sério é isto, da estória toda - por isto foi que a estória eu lhe contei - : eu não sentia nada. Só uma transformação, pesável. Muita coisa importante falta nome. Minha mãe estava lá no porto, por mim. Tive que ir com ela, nem pude me despedir direito do Menino. De longe, virei, ele acenou com a mão, eu respondi. Nem sabia o nome dele. Mas não carecia. Dele nunca me esqueci, depois, tantos anos todos. (idem, ibdem, 92)

Nesse trecho escolhido do Grande sertão: veredas, comumente chamado de "Primeiro encontro" ou de "Rito de passagem", foi possível apreender algumas características dos personagens, relacionando-as às funçōes apontadas por Vladimir Propp na Morfologia do conto maravilhoso. Porém, outras leituras poderiam se desenhar aqui. $\mathrm{O}$ menino de olhos esmartes, corajoso, que posteriormente se revelará como o jagunço Reinaldo Diadorim, aparece aqui, de certa forma, simbolizando finalmente o herói. No entanto, essa afirmação pode limitar outras possibilidades de abordagem. De fato, Diadorim foi uma espécie de paradigma na vida de Riobaldo, com a apresentação de uma perspectiva para um mundo novo, com a iniciação na coragem - com o enfrentamento do mistério.

Voltando ao início deste artigo, foi apresentada uma proposta, em seqüência, que expunha a saída de Riobaldo de casa, sobrecarregado por um interdito, isto é, o recolhimento da esmola para pagamento de uma promessa, mas, que antes de ser a tarefa um "fardo", tratava-se de uma via para a descoberta do mundo. Houve também uma sugestão de identificação, num primeiro momento, de Riobaldo como herói e a sua aproximação às funções enumeradas por Propp. No entanto, o surgimento do menino Diadorim provoca uma instabilidade nessa leitura, pois ele não se submete facilmente às características classificatórias. 
Por um lado, Reinaldo Diadorim pode ser tido como elemento mágico na travessia de Riobaldo, por outro, pode ser o herói, todavia, também o anti-herói - provocador dos dois pólos distintos e intercambiáveis: o Bem e o Mal. Qualquer posição que ele ocupe influenciará em outros papéis. A ambigüidade desse personagem, já nesse primeiro momento de aparição, é notória. $\bigcirc$ menino transmite paz, mas, também, inquietação. Nesse sentido, distancia-se um pouco da idéia do herói que restabelece a ordem das coisas. Ao contrário, ele suspende e evidencia a força e a fraqueza do mundo, alternadamente, como se a vida não pudesse ser explicada, finalmente, senão no movimento de travessia. Diadorim tem a face de Deus e do Diabo, simultaneamente. É o nada e o tudo, o achado e o perdido, na vida desse narrador Riobaldo, que dirige palavras sobre o sertão a um senhor ouvinte; mas, falando para si mesmo - em recordação. 


\section{Referências bibliográficas}

ROSA, João Guimarães (1986). Grande sertão: veredas. Rio de Janeiro: Nova Fronteira.

PROPP, Vladimir (1984) I. Morfologia do conto maravilhoso. (Trad. Jasna Paravich Sarhan). Rio de Janeiro: Forense-Universitária. 